\title{
Research on Urban and Rural Public Cultural Service System Under the Development of Digital Technology
}

\author{
HE Xiu-ying ${ }^{1, *}$
}

\author{
${ }^{1}$ Shengli College of China University of Petroleum, Dongying District, Dongying City, Shandong Province, China \\ *Corresponding author.Email: 373452199@126.com
}

\begin{abstract}
Digital technology can provide effective development strategies for urban and rural public cultural service systems. This article analyzed the opportunities and challenges brought by digital technology to the urban and rural public cultural service system and proposed three aspects to improve the system by using digital technology: improving the supply mechanism, innovating the management mechanism, and improving the guarantee mechanism.
\end{abstract}

Keywords: Digital technology, public cultural service management system, urban and rural public cultural services

\section{Introduction}

As stated in the "Decision" released on the fourth plenary session of the 19th central committee of CPC, the government should improve the urban and rural public culture service system. To meet the people's needs is the key to developing a rural and urban public culture service system. President Xi, on his visit to Shaanxi on 20 April 2020 , made a point of increasing supply of public cultural products and services to meet the spiritual and cultural needs of people. Therefore, construction of a public culture service system should explore quality cultural resources to meet the people's needs. Digital intelligence is a typical feature of digital technologies, and introducing digital technology is the driving power for construction of rural and urban public culture service systems.

\section{Benefits that digital technology brings to public culture service}

\subsection{Promoting integration of cultural resources}

With the development of digital technologies, the government can build public culture service platforms that gather cultural resources, breaks the limits of time and space and delivers excellent culture to the mass via big data and Internet technologies. The platform extracts culture of different places and different time to break away from the traditional monotonous culture sharing mode, preserve the traditional culture and hand it down to future generations. Integrating cultural resources using digital technologies increases the practical value of culture and avoids the "information island" situation.

\subsection{Improving the efficiency and quality of public culture service}

Data technology can be used to conduct scientific analysis of data on public culture service. The government should consider the regional culture features, conform to the supply-demand relations of public culture service, optimize the allocation of resources, cut the cost and improve the efficiency of public culture service.

\subsection{Balancing the rural and urban public culture service}

The imbalanced development of public culture service between cities and rural areas is an urgent problem to be solved. How to narrow the gap and balance the public culture service in rural and urban areas remains the core problem. Digital technology can be used in management systems of public culture service. Big data and Internet technology platforms can help orient quality culture resources and services to disadvantaged groups and underdeveloped regions, thereby narrowing the gap between rural and urban areas in public culture service.

\subsection{Improving the adjustment mechanism of public culture service standards}

The government should use big data, intelligence and Internet technologies to collect resources of public culture, improve the standards of public culture service, perform analysis and modelling of data systematically, continuously and repetitively, test the data according to people's needs, generate a dynamic adjustment mechanism to satisfy people's cultural demand. 


\section{Challenges in developing rural and urban public culture service systems based on digital data}

\subsection{Insufficient supply of urban and rural public culture service}

\subsubsection{Demand-supply imbalance between rural and urban areas}

(1) Imbalanced allocation of cultural resources. Since the 18th National Congress of the Communist Party of China, public culture service develops faster, but under the government-dominated development mode, the resources for development of public culture remain in shortage and the products are monotonous. The public culture resources are unevenly distributed: cities outweigh rural areas and central areas outweigh boundaries, thus unable to meet the needs of the mass. It is an undeniable fact that economic imbalance exists among regions in China, and imbalanced economic development will lead to imbalanced development of public culture service. The national investment to rural areas is much less than that to urban areas, therefore, the sufficient supply of public culture service in rural areas cannot be ensured. As a result, the efficiency and quality of public culture service in remote areas and poverty-stricken areas do not meet the standards. (2) Lack of awareness for public involvement and cultural activities. For long, the traditional public culture service system fails to motivate the mass to get involved in public culture service, and the public shows weak awareness for public culture service, thus curbing its development. The government does not perform well in promotion events, and lack of attraction for cultural resources is also a defect in traditional culture service. Therefore, the government should give wield its leadership, encourage people to take part in cultural events and to contribute to public culture endeavors.

\subsubsection{Lack of connection among regional cultural resources}

In these years, many cities respond positively to the national policy of developing public culture service systems via Internet, radio and TV networks, satellite networks, supplying public cultural resources to rural areas and creating rural digital studies for 125,000 households. However, the insufficient connection of resources remains. (1) Absence of resource sharing among departments of different regions. Absence of culture sharing among neighboring regions is the major manifestation of inadequate exchange of culture currently. Public culture service departments of different regions often repeat the same work and explore the same type of cultural resources, which causes waste of capital and labor resources and show lack of in-depth analysis.

(2) Lack of connection between different culture service platforms. Different regions build their own culture service platforms. Because there are no consistent standards for public culture resources, developers have constructed service platforms of different types and technologies, making it difficult for connection between platforms and share resources.

\subsection{Lack of innovation in urban and rural public culture service}

\subsubsection{Insufficient integration between cultural products and technology}

Combination of culture and technologies is a popular concept for the time being. One prominent example is the innovative digital promotion of the Forbidden City; culture service products based on "Internet + culture" and cloud travelling have been used in some regions. However, the traditional culture service mode still dominates in many regions, the reasons for which are as follows.

(1) The government has not completed upgrading of public culture service yet. Traditional public culture service modes still exist, and the idea of government innovation and upgrading is taking shape. The government is encouraging upgrading of public culture service, but it cannot be completed at a stroke. The traditional public culture service mode has already found ways into different culture service departments, and there is still a long way to go to integrate cultural resources with technologies.

(2) Immature integration of the culture industry and technology. The cultural industry and technology is still merging, and cannot be directly applied to public culture service systems. Many regions have built public cultural networks and established cloud travelling programs. However, problems like users' failure to $\log$ in and slow operations. Many problems reflect that integration of culture and technology is still in the initial stage, and mature products are to be developed.

\subsubsection{Defective management of public culture service}

The traditional culture service mode still takes dominance in supply of public culture service. The administrative and monotonous supply mode lacks efficiency and accuracy, unable to provide satisfaction to the mass.

Public culture service is closely connected to cultural policies and systems. Some administrative censorship procedures are complex and reduce the efficiency of culture departments. The upper management takes hold of the approval rights, making the community culture service hard to realize. The proposal red tape is onerous and thus culture activities cannot be implemented. 


\subsection{Defective guarantee mechanism for urban and rural public culture service}

\subsubsection{Defective financial support}

In 2019, the national investment into public culture service systems reached 22.5 billion yuan, an $8.17 \%$ increase than in 2018; the investment into cultural undertakings in poverty-stricken areas was 1.69 billion yuan, which manifested the increased investment of the government into development of public culture service. Yet, the following problems lurk.

(1) A defective feedback mechanism for digital public culture service

With increased financial investment into public culture service systems, the problem of financial waste emerges. The feedback system is still to be created in some regions, and the system fails to meet the needs of the public who are the served subjects. The digital technology applied to public culture service is mainly in the forms of online resources, electronic information platforms and videos. Development of public culture service infrastructure fails to consider the needs of the served subjects. Most financial investment has gone to large digital culture service products, such as 5G culture networks, but cultural products of regional characteristics are not developed. As a result, many regions fail to provide quality cultural resources despite the well-equipped cultural museums.

(2) Formalization of development of culture programs

Encouraged by the national policies, each region strives to develop public culture service systems, but problems emerge during the development. Some programs are mere frills and have no practical value, leading to a waste of resources. The major reason is that in some hard-to-reach underdeveloped regions, the public do not feel like to spend much time on the culture service, leading to idling of the cultural infrastructure. Consequently, the cultural resources lose its value. Therefore, in the planning stage, the government and public culture service providers should consider what the people really need, and think in the people's shoes to avoid waste of public cultural resources.

\subsubsection{Shortage of all-round talents for digital culture service}

In 2019, the central government assigned and trained about 19,000 cultural talents for poverty-stricken areas, boundary areas and revolution areas. It shows the government's increasing attention to development of talents for the public culture service systems in grass-root level communities and remote areas.

That being said, to apply digital technology to public culture service systems needs not only cultural workers, but those who are versed in digital technologies, or specifically, all-round talents with digital expertise. To develop a team of all-round talents should expand the channel of introduction of talents, inject more blood to the public culture service systems. First of all, public culture providers should cooperate with the local government to improve the talent enrollment system to draw more talents and create a fair and just environment of recruitment. Secondly, the talent cultivation system should be improved to improve the recruits' expertise, design training plans, enhance their professional skills and public culture service awareness via professional training and advanced training, freeing them from entrenched traditional mindset, improving their sense of innovation, their cultural literacy and personal qualities.

\section{Strategies to develop public culture service management systems using digital technology}

\subsection{Improving the supply mechanism of urban and rural public culture services}

\subsubsection{Using digital technologies to balance public culture service in rural and urban areas}

(1) Preferential policies. In 2015, the Chinese government issued "Outline for development of public culture service systems in poverty-stricken areas in the " $13^{\text {th }}$ Five Year Plan"”; in 2016, the government released the "Guiding opinions of developing characteristic industries in povertystricken areas to realize targeted poverty alleviation"; in 2017, the Ministry of Culture issued "Plans for cultural poverty alleviation in the " $13^{\text {th }}$ Five Year Plan"'. All these policies aim to balance the public culture service in rural and urban areas and seek to improve the public culture service systems. It is sure that the government will issue more policies to develop more precision public culture service.

(2) Selecting quality cultural products. The fourth plenary session of the $19^{\text {th }}$ Committee of CPC proposed that we should hold up to the people-oriented development idea and strive to improve the supply of urban and rural public culture service. Therefore, the very core of improving urban and rural public service systems is to select quality public cultural products. Using digital technologies, the government can develop databases to sort cultural products of different types and provide cultural products that meet the needs of different groups according to the regional features.

(3) Improving basic infrastructure for public culture service. It is necessary to strengthen development of digital cultural service, develop demonstration zones for public culture systems, identify culture service indicators on the basic level, and promote public cultural service in remote rural areas. It should also promote drama and opera culture to rural areas and develop comprehensive culture service centers. 


\subsubsection{Using digital technology to improve integration and connection of regional public culture service resources}

Cities should provide more support for rural and poor areas in cultural programs, build connected public culture service systems, integrate cultural resources, develop cultural resource sharing platforms in culture service demonstration zones, expand the platform's coverage, and reduce the cost of cultural resource development. The government should introduce more quality culture to remote and underdeveloped regions and strengthen the development of interconnected culture service networks. The digital technology should be fully used to build diversified public culture service platforms.

\subsection{Innovating the public culture service management system based on digital technology}

\subsubsection{Using digital technology to develop innovative measures for public culture service management}

(1) Introducing digital cultural products. Opening of the WeChat account of "The Sound of Culture and Tourism" and the TikTok account of "Ministry of Culture and Tourism" has broken the limits of traditional public culture service. In August 2019, the WeChat account provided new modules of categorized search, online administration and travel \& culture matrix. As of 31 December 2019, the WeChat account had released 1296 articles and attracted 232,000 followers. The Weibo account has released 1090 pieces of information and drawn 434,000 followers. The TikTok account won 70 million clicks with the "evening gala for celebration of the National Day", with the highest view of one single video reaching 30 million. Utilization of these digital technologies has made some achievements. Therefore, the government should use digital technologies including big data and cloud computing technologies, and innovative management measures to make in-depth analysis of public culture service, establish proper service standards, promote scientific, standardized and precise public culture service, expanding the coverage of public culture service, creating a nationwide online public culture service system and developing a creative public culture service management mechanism.

(2) In-depth integration of culture and technologies. To improve synergy of technology and culture and meet the need of culture systems for technologies, we must improve the creativity for cultural technologies and improve the efficiency. Seven departments in Shandong jointly issued the "Opinions to promote in-depth integration of culture and technologies in Shandong", which proposed strengthening R\&D of key technologies in culture, developing a new "Internet + " mode of culture, and promoting in-depth integration with media.

First of all, technological advancements should be used to develop culture service platforms, support technological research, keep up with key information projects, realize digital development of culture service, create standard digital culture service networks, build service platforms that integrate culture with technologies, create digital platforms for public culture resources, public information technology service platforms and cultural technological achievement transformation platforms. Secondly, the government should improve the capacity to supply cultural resources, make scientific plans for public culture resources, encourage integration of excellent Chinese culture, and produce excellent cultural products. Last, to protect and inherit excellent traditional culture, the government should promote use of cultural resources in intelligence fields, providing customized service for the public.

\subsubsection{Using digital technology to promote transformation of public culture service in rural and urban areas}

Currently, the central and regional governments should prioritize exploration of the supply methods. With support from the government, the limits of traditional supply methods have been overcome and some progress has been made.

By optimizing the public service function of the government, culture service providers should innovate the culture treatment mechanism, use information technology to integrate social resources to realize modernized supply and production of cultural products, transforming the administrative and monotonous supply mode into a socialized, diversified and informatized supply mode, improving the efficiency, precision of supply of culture and increasing the public's satisfaction. Digital technologies can be used to improve culture service, develop online information service platforms, provide timely information and culture service for the residents, improving the work efficiency of workers and the service mode.

\subsection{Improving the public culture service guarantee system for rural and urban areas}

\subsubsection{Improving the financial guarantee mechanism for public culture service}

(1) Improving the feedback mechanism for public culture service

Digital technologies should be used to develop a feedback platform for public culture service. Different regions can build feedback platforms via Internet and big data 
technologies, provide feedback upon the efficiency of financial investment into culture services to evaluate the effect of public culture service. Online voting and online opinion collection programs can be initiated to make scientific analysis of culture needs of the public via digital technologies, summarize experience and conclude cultural activities that can encourage public involvement.

(2) Increasing the performance of financial policies in public culture service

The financial investment into culture service is largely stable. From 2016 to 2018, the investment into culture, tourism, sports and media reached 5.5154291 billion, 5.9285390 billion, and 5.4271771 billion, and the budget for 2019 is 4.6232019 billion, which shows a slight decline. These data demonstrated the stable investment of the government into public culture service. However, the outcome seems disappointing. Most culture programs are mere frills. Responsible departments should strengthen supervision of financial expenditure, develop programs according to the public needs and ensure positive outcomes of financial investment.

\subsubsection{Improving the talent selection mechanism}

(1) Strengthening talent training. Resources of different departments should be integrated to develop creative talents and improve the talent training system for public culture service, encourage training of professional and allround talents via cooperation between universities and enterprises, motivate talents of digital technologies to take part in practice in the field of public culture service, encourage industries to establish digital talent evaluation systems.

(2) Introducing new talents. Specific policies should be established to draw more talents from abroad. Specific service organizations should be provided to digital technical talents and preferential policies to draw digital talents should be released. To draw more talents, the government should develop creative mechanisms suitable for digital culture service talents.

(3) Creating a good environment for talent development. The key conditions to keep talents are as follows. First of all, there should be a preferable environment to attract and develop talents that provide benefits for the talents, a good living and work environment that ensure the talents' further development; secondly, the government should strengthen training of grass-root level government staff in digital technologies, assess the training results on a regular basis, incorporate the evaluation into the staff's annual performance appraisal to ensure smooth progress of public culture service.

\section{Conclusion}

To develop urban and rural public culture service systems based on digital technology, the key is to introduce digital technologies into the traditional public culture service supply modes in rural and urban areas, construct digital public culture service systems, promote balanced culture services in rural and urban areas, and use digital technologies to promote the government's initiatives to innovate the public culture service.

\section{ACKNOWLEDGMENT}

This work was supported by Humanities and Social Sciences Research Project of Shandong Higher Education Institutions (J16WF18), Art Science Key Topics of Shandong Province (ZD201906488) and (ZD201906363).

\section{REFERENCES}

[1] Juan Li; Likun Cai; Jinyu Li. Research on Comprehensive Evaluation of Public Cultural Service Level by Using AHP Method International Journal of uand e- Service, Science and Technology, 30 January 2016, Vol.9(1), pp.337-348

[2] Wang Ping; Hong Jin; Zhishi guanli luntan, A Content Analysis on Policy Trends of Chinese Public Cultural Service,01 October 2018, Vol.3(5), pp.275-290.

[3] Juan Li; Likun Cai; Lixian Jing, Research on the Public Cultural Service Upgrade Based on Structural Equation, International Journal of Database Theory and Application, 30 January 2016, Vol.9(1), pp.97-108

[4] Yingjun Han; Rui Sun, Research on the Performance Evaluation System of Public Cultural Service based on Web Survey: A Government Perspective International Journal of Security and Its Applications, 30 April 2016, Vol.10(4), pp.355-366

[5] JIA Xiao-min, ZHAN Li-xin, SUN Sheng-he, LUO Li-li, Research on Standards System of Public Cultural Service, World Standardization \& Quality Management, 2015, Issue 12, pp.43-47

[6] Wei Chen. Study on the Role of "Cultural City" in Promoting the Service System of Urban Public Libraries[C]. Institute of Management Science and Industrial Engineering. Proceedings of 2019 4th International Symposium on Management, Economics, E-business and Marketing (ISMEEM 2019). Institute of Management Science and Industrial Engineering: (Computer Science and Electronic Technology International Society), 2019:406-410. 